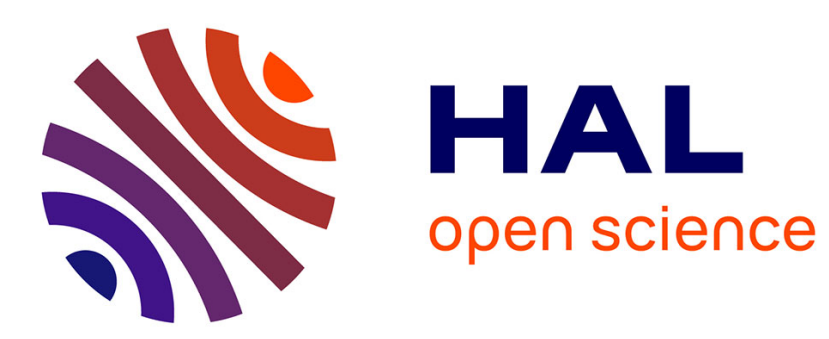

\title{
A model for analysing the innovation dynamic in services: the case of 'assembled' services
}

\author{
Faridah Djellal, Faïz Gallouj
}

\section{To cite this version:}

Faridah Djellal, Faïz Gallouj. A model for analysing the innovation dynamic in services: the case of 'assembled' services. SEM 2007, Service engineering and management summer school, Helsinki University of Technology, Sep 2007, Helsinki, Finland. 10.1504/IJSTM.2008.019702 · halshs-01113871

\section{HAL Id: halshs-01113871 \\ https://shs.hal.science/halshs-01113871}

Submitted on 6 Feb 2015

HAL is a multi-disciplinary open access archive for the deposit and dissemination of scientific research documents, whether they are published or not. The documents may come from teaching and research institutions in France or abroad, or from public or private research centers.
L'archive ouverte pluridisciplinaire HAL, est destinée au dépôt et à la diffusion de documents scientifiques de niveau recherche, publiés ou non, émanant des établissements d'enseignement et de recherche français ou étrangers, des laboratoires publics ou privés. 
SEM 2007, Service engineering and management summer school, 9-12 September 2007, Helsinki University of Technology, Helsinki, Finland

\author{
A model for analysing the innovation dynamic in services: the case of \\ 'assembled' services"
}

Faridah Djellal and Faïz Gallouj

Clersé, Ifrési-CNRS

\author{
(Published in International Journal of Services Technology and Management)
}

\begin{abstract}
:
This article examines the question of innovation in a particular group of services, namely 'assembled' services, such as hotels, retailing and distribution, hospitals, theme parks, etc. These are complex services produced by combining a variable number of other constituent services. Drawing on findings from the economics of services and the economics of innovation, we begin by developing a simple framework for analysing the output of services that are 'assembled' in nature, in which the main service provided is integrated into a complex system of other constituent services that call on various types of technologies and competences. This framework is then used to highlight the various principles driving innovation in this type of service.
\end{abstract}

Keywords : 'assembled' services, innovation

\title{
1 Introduction
}

Services make up a (large) family of economic activities whose kinship is not always easily established. The traditional definition of services, based on the criteria of intangibility, interactivity and immediacy, is regularly questioned. Indeed, these activities often fail to meet one or several of these criteria. There is no shortage of examples - whether in distribution, catering or transport - of services that have close links with tangibility, involve a low level of interactivity or can lay claim to a certain form of stockability, particularly under the growing influence of information and communication technologies. Conversely, intangibility and, above all, interactivity (the service relationship or servuction) are creeping into the heart of industrial production, just to blur the traditional boundaries. Thus there are many producers of goods - whether they be turning out potatoes, buildings, textiles or motor vehicles who are not employing a mere figure of speech when they describe their production activities as predominantly intangible and based on the service relationship (Nahon and Nefussi, 2002; Bougrain and Carassus, 2005 ; Lenfle and Midler, 2003, Bröchner, $2005,2006)$. The task of defining services, initiated by the classical economists, is far from complete, as recent theoretical debates have demonstrated (Hill, 1999 ; Gadrey, 2000).

\footnotetext{
${ }^{*}$ We would like to thank for their valuable input the anonymous referees.
} 
The diversity of service activities is probably in no small measure responsible for the diversity of approaches that have been taken to innovation in services (Gallouj, 1994, 2002; Sundbo, 1998; Metcalfe and Miles, 2000). Literature surveys generally take account of this diversity by making a distinction between technologist approaches (which emphasise the adoption of technological innovation by service firms), servicebased or demarcation approaches (which seek to highlight the specificities of innovation in services) and integrationist or synthesis approaches, whose aim is to develop new models that can be applied to all economic sectors and to all forms of innovation (Gallouj, 1994, 2002).

This article is given over to innovation in a particular group of services that we will call 'packaged' or 'assembled' services. These are complex services produced by assembling a variable number of other services. This is the case, for example, with hospital or hotel services, retailing, tourism, theme parks, air transport etc. The question of innovation arises in a particular way here, to the extent that it has a systemic dimension since it concerns both the various constituent services and the assembly or 'package' as a whole.

Drawing on some recent findings in the economics of services and the evolutionary economics of innovation, we put forward a simple model for analysing the product of 'assembled' services, which are defined as the aggregate of certain constituent services, which are themselves considered in terms of a functional and technological breakdown $^{1}$ (section 2). Dynamic implementation of this model provides the basis for developing a systematic framework for analysing the principles driving innovation in this type of activity (section 3). These various principles are then illustrated by numerous examples drawn both from empirical investigations we have carried out and a survey of the relevant literature (section 4). Thus the approach developed here is both service-based, to the extent that it is concerned with the specificities of a particular group of services, and integrationist, at least as far as the diversity of forms of innovation is concerned, since it seeks to take account of all innovation, regardless of its nature. The analytical framework provided aims at improving our theoretical knowledge of a still underdeveloped area ie. innovation in services, but it can also be used as an audit or prospective and strategic tool, for surveying innovation within 'assembled services' and for identifying new fields of innovation.

\section{2 'Assembled' services: a model for analysing output}

'Assembled' services can be defined as the provision of a package of services, which vary in type and number and are linked or integrated with each other in various ways. This package acquires institutional visibility and autonomy, in such a way that it cannot be reduced to the sum of its constituent parts. Our aim here is, firstly, to demonstrate the value of and the theoretical difficulties inherent in implementing such a level of analysis and, secondly, to advance a simple model for analysing this particular product or output.

\section{1 'Assembled' services as a relevant analytical category}

\footnotetext{
${ }^{1}$ This is an analytical framework that we developed initially in order to examine innovation in hospital services (Djellal et al., 2004; Djellal and Gallouj, 2005) but which is extended here to all 'assembled' services.
} 
Bressand and Nicolaïdis (1988) use the neologism 'compack' ('complex package') to denote these 'assembled' services. Such services should not be regarded in simply mechanical terms. The whole is greater than the sum of its parts. In other words, the packaging of constituent services within a given 'packaged' level helps to create an additional product or leads to the identification of a different product. For example, to confine ourselves to a very familiar case, the Club Med 'product' cannot be reduced to a mechanical package of transport, hotel, catering and leisure services. The combination of these services introduces an additional element, which smoothes the joints between the different constituent services and gives this 'compack' the status of a different product.

This level of analysis is not self-evident. It raises a number of difficulties.

One might be tempted to regard all service activities as 'assembled' services, to the extent that they provide a diversified range of 'service products'. This would not be a fruitful approach. Thus the service provided by a hospital is an 'assembled' service (combining medical, cleaning, catering and hotel services) but except for a few number of very large international audit and consultancy firms, it does not seem useful to use such a definition for consultancy services. Consequently, the notion of an 'assembled' service is subjective and governed by convention. 'Assembled' services are packages of constituent services that generally have an historical and institutional existence (for example, because they are identified in the standard typologies and accounting classifications).

'Assembled' services raise the question of where the boundaries of their complex products are located. Such boundaries are porous and mobile. They are also defined by convention. Thus 'air transport', another 'assembled' service, comprises both the various constituent transport services but also the services provided by airports. Another difficulty is the level of analysis that should be chosen. Thus air transport can be regarded as an 'assembled' service. However, tourism is another 'assembled' service that encompasses the previous one.

The technical criteria for qualification as a service (intangibility, interactivity, immediacy) cannot be used to define these 'assembled' services, since each constituent service in the package can be characterised differently on the basis of these criteria.

Similarly, the image of the service triangle (Gadrey, 1996) can be used to define each constituent service (or each element of a constituent service), but the 'assembled' service as a whole is a complex combination of service triangles that are interconnected to a greater or lesser extent by means of various procedures (succession in time, simultaneous delivery, etc.). Thus the provision of an 'assembled' service is characterised by diversity: diversity of service media, of actors, of service relations and of appropriation regimes. It is also characterised by this fundamental contradiction (this dialectical relationship) between diversity and the construction or preservation of a single entity.

'Assembled' services are also a particularly complex object because they cannot be reduced to a single service principle in accordance with Gadrey's definition (Gadrey, 2000), which distinguishes three different service principles: the assistance or 
intervention principle, the provision of technical capacities principle (capacities that customers can pay to use) and the human performance or live entertainment principle. Rather, 'assembled services' combine all the existing principles.

\subsection{A model for analysing the 'product' of 'assembled' services}

An 'arithmetic' definition of 'assembled' services as the sum of other services is insufficient to fulfil our objective, which is to develop the most comprehensive framework possible for analysing innovation. To do this, it is essential to investigate the 'black box' of each constituent service. This is what we propose to do, drawing on the above-mentioned studies by Hill $(1997,1999)$ and Gadrey $(1996,2000)$, which we combine with a Lancasterian approach to services based on the notion of characteristics (Gallouj and Weinstein, 1997; Gallouj, 2002).

The provision of an 'assembled' service is a complex activity that can be defined by linking the following four variables (cf. Table 1):

1) the constituent services $\left(\mathrm{S}_{\mathrm{i}}\right)$ of which it is made up;

2) the media or targets of the service to be provided;

3) the service characteristics obtained or desired;

4) the competences of the service providers.

\subsubsection{The constituent services (Si)}

We can make use here of the distinction frequently made in management sciences between core and peripheral services. A core service is the one that basically defines the 'assembled' service in question. In the case of a hospital, this would be the provision of medical care, of overnight accommodation in the case of a hotel, transport in the case of an airline, the attractions in the case of a theme park and the sale of goods in the case of a retail firm. However, the provision of an 'assembled' service cannot be reduced to these core services, since it comprises many other services as well (cf. Table 1). These peripheral services serve to enhance the core service or to facilitate access to it, although they do not usually in themselves justify the customer's demand for the service in question.

Table 1 'Assembled' services and their constituent services

\begin{tabular}{|c|c|c|}
\hline 'Assembled' service & Core constituent services & $\begin{array}{l}\text { Peripheral constituent services (some } \\
\text { examples) }\end{array}$ \\
\hline Hospital & $\begin{array}{l}\text { Medical treatment/nursing } \\
\text { care }\end{array}$ & $\begin{array}{l}\text { Accommodation, maintenance, reception, } \\
\text { transport, management-administration, } \\
\text { catering, crèche, laundry, leisure, funeral } \\
\text { parlour, retail outlets, cleaning, waste } \\
\text { processing }\end{array}$ \\
\hline Theme park & $\begin{array}{l}\text { Visitor attractions, } \\
\text { entertainment, parades }\end{array}$ & $\begin{array}{l}\text { Catering, transport and traffic flows } \\
\text { (internal and external), accommodation, } \\
\text { cinemas, discotheques, conferences, } \\
\text { retail outlets, cleaning, etc. }\end{array}$ \\
\hline Large-scale retailing & Sale of goods & $\begin{array}{l}\text { Travel agencies, banking services, } \\
\text { insurance services, photographic } \\
\text { services, catering services, delivery }\end{array}$ \\
\hline
\end{tabular}




\begin{tabular}{lll} 
Hotel & Overnight accommodation & $\begin{array}{l}\text { Catering, leisure services, parking, } \\
\text { conferences, laundry, security etc. } \\
\text { Catering, retail outlets, leisure services, } \\
\text { telecommunications, religious services, } \\
\text { etc. }\end{array}$ \\
\hline
\end{tabular}

\subsubsection{The main target of service provision $(M, I, K, R)$}

In accordance with the notion of the service triangle (Gadrey, 1996), the provision of a service consists of a set of operations affecting various media or targets, namely material objects (M), information (I), knowledge (K) or individuals (R).

Thus four groups of operations can be identified (Gadrey, 1996; Gallouj, 1999) which, depending on the service and time in question, are combined in differing proportions each time the constituent service $\left(\mathrm{S}_{\mathrm{i}}\right)$ is provided: 1) material transformation operations $(\mathrm{M})$; 2) information processing operations (I); 3) operations involving the intellectual processing of knowledge $(\mathrm{K})$ and 4$)$ contactual or relational service operations $(\mathrm{R})$.

The nature of these operations differs of course, depending on the type of target. In the first case, the targets are tangible objects that have to be processed in some way, i.e. transported, transformed, maintained, repaired etc. In the second case, it is codified information that has to be produced, captured, diffused, stored or revealed. In the third case, the processing is based on codified methods and routines and intangible technologies. The fourth and final case, in which the main medium is the customer, involves the provision of a direct service with a greater or lesser degree of interactivity with the customer.

Each of these groups of operations can be associated with particular families of technologies and the corresponding scientific and technological disciplines. The proposed functional breakdown of the product is also, to some extent, a scientific and technological breakdown. This is particularly evident in the case of the first three groups of operations, which correspond, respectively, to material processing technologies (robotics, mechanics etc.), information processing technologies (computers, telecommunications, etc.) and cognitive technologies (intangible technologies, methods etc.), what Berry (1983) calls 'invisible technologies'. As for the relational component, it can be associated with each of the preceding disciplines and with others, particularly the humanities and social sciences.

\subsubsection{The basic service characteristics or use values (Y)}

Considered from the user's point of view, service characteristics (which should not be confused with the constituent services) are utility (in the sense of the term specific to economic theory) derived from the deployment of the internal technical components and/or competences in the course of the various types of operations that make up the service provision. They are located 'downstream' of our breakdown of output (or product). 
In the case of goods, identification and designation do not generally pose any particular problem. In the case of services, this exercise varies in difficulty depending on the type of constituent service under consideration. However, this difficulty does not call into question the theoretical relevance of this category, since services, like goods, provide services. Unintentional service functions or characteristics, that is perverse effects or negative externalities, could be added to these (desired) service functions or characteristics. They might include, for example, the contraction of nosocomial diseases in hospitals, congestion in hypermarkets and theme parks, strikes and delays on the railways or at airports, etc.

\subsubsection{The service providers' competences $(C)$}

The service providers' competences are located 'upstream' of our breakdown of the service. They may be competences in the technologies deployed and the various types of operations carried out or they may be competences that are directly mobilised, without any technical mediation, in order to produce service characteristics (Y). These competences may be scientific and technical in nature, or they may be relational, creative or operational (manual). They are derived from various sources: initial or continuing training or education, experience and, more generally, various forms of interaction and sources of learning. They may be validated by a professional body or some other system for verifying qualifications.

Thus Table 2 provides a relatively simple representation of the 'output' of an 'assembled' service from both the functional and technological points of view. That output can be represented as the aggregate of various constituent services $\left(\mathrm{S}_{\mathrm{i}}\right)$ which, in turn, can be seen as combinations, to varying degrees, of basic operations carried out on objects, information, knowledge or individuals. Columns M, I, K and R in the table are 'internal' functions or components of the output, whereas columns $\mathrm{C}$ and $\mathrm{Y}$ are external functions. $\mathrm{C}$ is located, as it were, upstream of service delivery and $\mathrm{Y}$ is located downstream of it. This means that the competences play a part in the implementation of the corresponding operations and technologies, which in turn are translated into the provision of service characteristics.

It will be noted that the proposed analytical framework can be used at various analytical levels, depending on requirements and the characteristics of the particular 'assembled' service under consideration. This framework can be applied at the organisational or institutional level (for example, a hospital or hotel in its entirety, a hypermarket or a theme park), as well as at the intra-organisational and interorganisational levels.

Thus at the intra-organisational level, if the service in question is a "package of packages' of constituent services, each $\mathrm{S}_{\mathrm{i}}$ can itself be broken down into a set of constituent services $\mathrm{s}_{\mathrm{ij}}$, which could constitute independent units of analysis. Thus in the case of a hospital, the generic constituent service denoted by the label 'medical treatment/nursing care' $\left(\mathrm{S}_{\mathrm{i}}\right)$ can be regarded as a package of constituent services $\mathrm{s}_{\mathrm{ij}}$, which might include, for example, treatment and nursing care, tests, radiology, surgery, rehabilitation, anaesthetics, consultations, etc. In a hypermarket, the core constituent service 'supply of goods' can similarly be broken down into a number of other services, even if that simply involves marking off the various specialist departments from each other. 
The inter-organisational level, for its part, takes account of various inter-related organisations, which could themselves possibly be defined as packages of constituent services: for example, the establishment of relations between a hospital and other health care centres, doctors in private practice, voluntary associations or local authorities, or the establishment of links between a hypermarket, its suppliers and haulage companies or between a theme park, travel agencies, tour operators or works councils etc.

Table 2 : A framework for analysing the output of an 'assembled' service

\begin{tabular}{|c|c|c|c|c|c|c|}
\hline $\begin{array}{l}\text { Constituent } \\
\text { services }\end{array}$ & $\begin{array}{l}\text { Competences } \\
\text { mobilised }\end{array}$ & \multicolumn{4}{|c|}{$\begin{array}{l}\text { Service medium, corresponding operations or functions and associated } \\
\text { technologies }\end{array}$} & \multirow{2}{*}{$\begin{array}{c}\text { ('External') } \\
\text { use, final or } \\
\text { service } \\
\text { characteristics } \\
\text { or functions } \\
\text { Y } \\
\text { Service } \\
\text { functions and } \\
\text { characteristics } \\
\text { (+ } \\
\text { corresponding } \\
\text { disciplines) }\end{array}$} \\
\hline $\mathrm{S}_{\mathrm{i}}$ & $\begin{array}{c}\text { C } \\
\text { Competences in } \\
\text { (the use of) } \\
\text { technologies or } \\
\text { competences } \\
\text { directly } \\
\text { mobilised }\end{array}$ & $\begin{array}{c}\text { M } \\
\text { 'Material' } \\
\text { operations } \\
\text { (+ corresponding } \\
\text { sciences and } \\
\text { technologies) }\end{array}$ & $\begin{array}{l}\text { I } \\
\text { 'Informational' } \\
\text { operations } \\
\text { (+ corresponding } \\
\text { sciences and } \\
\text { technologies) }\end{array}$ & $\begin{array}{c}\text { K } \\
\text { 'Methodological' } \\
\text { operations } \\
\text { (+ corresponding } \\
\text { sciences and } \\
\text { technologies) }\end{array}$ & \begin{tabular}{l}
\multicolumn{1}{c}{$\mathrm{R}$} \\
Contactual or \\
relational service \\
operations \\
(+ corresponding \\
sciences and \\
technologies)
\end{tabular} & \\
\hline \multicolumn{7}{|l|}{$\begin{array}{l}\mathrm{S}_{1}(\mathrm{Si} 1, \quad \mathrm{Si} 2, \ldots \\
\mathrm{Sij}, \ldots \mathrm{Sim})\end{array}$} \\
\hline \multicolumn{7}{|l|}{$\mathrm{S}_{2}$} \\
\hline \multicolumn{7}{|l|}{$\mathrm{S}_{3}$} \\
\hline \multicolumn{7}{|l|}{$\ldots$} \\
\hline \multicolumn{7}{|l|}{$\mathrm{S}_{\mathrm{i}}$} \\
\hline$\ldots$ & & & & & & \\
\hline $\mathrm{S}_{\mathrm{n}}$ & & & & & & \\
\hline
\end{tabular}

The general analytical framework, which is outlined in Table 2, seems to us to be a useful tool, firstly for conducting detailed analyses of the various dimensions of the output of 'assembled' services and then for considering, in a structured and systematic way, the question of its evolution and transformation, that is the question of innovation.

\section{A framework for analysing innovation in 'assembled' services}

The framework for analysing the output of 'assembled' services outlined above constitutes an attempt to break into the 'black box' of this family of services. It is also a general framework for analysis of innovation in this type of activity, one that makes it possible to highlight the diversity of forms of innovation in 'assembled' services. This diversity can be captured by reference to a limited number of organising principles driving innovation in these services. As we shall see, these organising principles can be described as extensive, regressive, intensive and combinatory.

\subsection{The extensive and regressive principles}

The extensive and regressive principles are described together, since they are substantially similar in that they both act on the rows of the table.

The extensive organising principle leads to rows being added to the table. In other words, constituent services $\left(\mathrm{S}_{\mathrm{i}}\right)$ are added to the existing service, while the regressive principle involves the elimination of constituent services, that is the elimination of 
rows from the table. The extensive principle is frequently at work in diversification strategies. Extending the range of services on offer and competing on the range of services provided seem to be important elements in the strategies adopted by providers of 'assembled' services. On the other hand, it may seem paradoxical to link the terms innovation and regression. It is nonetheless the case that, in many service activities, the innovation process may involve a reduction in service(s).

\subsection{The intensive organising principle}

The intensive organising principle is reflected in a (positive or negative) action on the columns of our analytical framework. Thus for a given constituent service $S_{i}$, it involves acting in various ways on the internal or external components of the product. New competences and/or (tangible or intangible) technologies may be added, a process that may be accompanied by the elimination of old competences and/or technologies. Conversely, the weight (value) of existing competences and/or technologies might be increased or, in some cases, reduced.

Within this intensive organising principle, four innovation trajectories can be identified: a material transformation trajectory, an information processing trajectory, a methodological and cognitive trajectory, and a relational trajectory.

1. The material transformation trajectory manifests itself in the material transformation component of the service. It reflects technological developments relating to the transportation and transformation of material substances (transportation systems for people or equipment, cooking and refrigeration systems, cleaning systems, various kinds of dispensing machines, visitor attractions, bio-medical or biopharmacological innovations, etc.). This trajectory is often described as a 'natural' trajectory in Nelson and Winter's sense of the term (Nelson and Winter, 1982), that is a trajectory based on increasing mechanisation and exploitation of economies of scale.

2. The information processing trajectory equates, self-evidently, to the dynamic of information and communication systems and manifests itself in the product's informational component. It is characterised in particular by a trend towards the reduction of communication costs, networking and the production of new information and of new ways of using information.

3. The methodological trajectory encompasses the production and evolution of formalised methods of knowledge processing. It plays an extremely important role in knowledge-intensive services such as consultancy, engineering, etc. (Toivonen, 2004). However, it also plays a role in some operational services, such as cleaning or transport (Djellal, 2000 ; Sundbo, 1996, 1998).

4. The relational trajectory concerns the 'contactual service' element, which also has its own innovation dynamic. It describes the introduction of contactual service functions or characteristics or new ways of bringing together customers and service providers, as well as their evolution over time. It is difficult to separate this relational trajectory from the others. The customer/user interface or contactual service operations can evolve by mobilising competences alone or through the use of material, information or knowledge processing technologies 


\subsection{The combinatory principle}

The extensive, regressive and intensive principles are ideal types. They are valuable heuristic devices for understanding the diversity of forms of innovation in 'assembled' services. Nevertheless the fourth organising principle driving innovation - the combinatory principle - is the commonest and most concrete operational mode. It draws on the 'pure' basic mechanisms outlined above, which it links in number of different ways, thereby preventing a 'fragmented' analysis of innovation.

In our analytical framework (Table 2), this combinatory principle impacts not on a particular row or column but rather on several rows and/or columns, which are combined or separated in order to produce an innovation. The innovation process here is similar to a puzzle game, in which various squares on a grid are combined to obtain a new service. This combinatory principle can be considered at the organisational, intra-organisational and inter-organisational levels.

There are very many examples of innovations derived from this combinatory principle. The architectural or combinatory process can vary in scope and complexity (i.e. it may cover a variable number of squares on the analytical table). However, the combinatory principle can express itself at other levels. Thus different technologies (columns in the table) and the corresponding trajectories can be combined in various ways. They can be used together, while remaining 'separate', in order to produce given service characteristics. In that case, the technological trajectories exist independently of each other. The combinatory principle manifests itself simply in independent coexistence within the same organisation or department. However, the corresponding technologies (columns in the table) and trajectories can also be combined. In this case, the combinatory principle manifests itself in the existence of a single technology resulting from the hybridisation of different technologies and trajectories.

\section{Some illustrations}

The frameworks for analysing output and innovation developed above are general in their scope. They can be applied to all 'assembled' services. In this final section, we take a small number of services of this kind and offer some more detailed illustrations drawn from both empirical investigations and a survey of the professional literature. Our examples are taken from the following three types of organisations: hospitals, large retail outlets and theme parks.

\subsection{Hospitals}

Our concept of a hospital as an 'assembled' service marks a shift of perspective away from the technicist approach towards an approach to innovation based on service and the (internal and external) service relationship. Patients are not simply sick people in need of treatment but also customers of a complex service-providing organisation that has to make every effort to satisfy not only the customers themselves but also their families and relatives. Thus innovation in hospitals shouldn't be analysed only as a black box (through the production function concept). It shouldn't be any longer considered merely as the sum of more or less highly developed and spectacular medical technologies. And it cannot be reduced to a sophisticated and tentacular 
information system. If innovation in hospitals is to be captured in its totality, it is necessary to break into the black box of the organisation. Penetrating the black box in this ways puts the spotlight on the actors in innovation and on support functions (accommodation, catering, laundering, transport, etc.) that are also neglected. This multiplicity of forms of and actors in innovation can be captured by means of the organising principles highlighted by our analytical framework. ${ }^{2}$

a) The extensive principle

The constituent services added in accordance with the extensive principle may be drawn from any of the major groups of services in the hospital package. Innovation in hospitals (as well as research into innovation in hospitals) tends to focus on medical and paramedical services. However, the other groups should not be ignored, since they have considerable potential for expression of the extensive organising principle: services of the accommodation-catering-retailing type, services of the administrationmanagement type.

There are very many examples of innovations falling within the scope of this extensive principle. We will confine ourselves here to examples drawn from nonmedical services. Some of them are well known. This is the case, for example, with bookshops, gift shops, mini-supermarkets, florists, toy shops, photographers, pharmacies, hairdressing salons, recreational activities for children in hospital, sports and fitness facilities for adults, childminding services, etc. Others are less conventional. They include banks, shoe repairers, dry cleaners, travel agencies, legal advice units, photographers, hairdressers (Swindley and Thomson, 1992) and the provision of training in such areas as bicycle repairs, dance, clown skills and handling divorce (Sasaki, 2003).

\section{b) The regressive principle}

Unlike regional and/or teaching hospitals, local hospitals are characterised by a minimal set of technical capacities and reduced services, which could be interpreted as resulting from the elimination of many of the constituent services provided by regional and teaching hospitals. This is the same 'minimum service' principle that is found in the fast-food industry, for example, in charter and low-cost flights and in discount stores (cf. section 4.2) and budget hotel chains.

The regressive principle is also at work in the extreme specialisation strategies adopted by some hospitals. Teboul (1999) cites the example of a private clinic that treats only patients suffering from inguinal hernias and which refuses to operate on, for example, obese people suffering from hernias or patients declaring a history of heart disease. Many other examples could be cited, including hand surgery, eye surgery and treatment for diabetic foot lesions.

c) The intensive principle

\footnotetext{
${ }^{2}$ For a more detailed analysis of innovation in hospitals, cf. Djellal et al. (2004) and Djellal and Gallouj (2005).
} 
There are many examples of innovations falling within the scope of the material trajectory. They can be divided into two groups, depending on whether the process in question is medical or non-medical in nature. As far as technologies for the (nonmedical) 'processing' of physical or human matter are concerned, examples might include motorised beds, new food transport systems, multi-functional vehicles adapted for the many different needs of hospital logistics, new equipment for processing hospital waste and robots used for cleaning. Turning now to the technologies used in the (medical) processing of human matter, examples include the introduction of new or improved drugs and the introduction of new technical systems or small items of equipment (e.g. the replacement of electric scalpels by ultrasonic dissectors).

The informational trajectory is, of course, particularly important in services relating to the management and administration of information flows. Examples include the collection of hospital revenue at automatic payment stations, the development of an interactive system for use in drawing up nurses' work schedules in the various departments and clinics of a teaching hospital and the establishment of ultrasophisticated processing and dispatching centres for emergency calls. However, this informational trajectory is also becoming increasingly evident in the management of material flows (stock management, kitchen management, etc.) and in medical services (telemedicine being the most significant example).

In the case of hospitals, the methodological trajectories are evident, once again, in both medical and non-medical services. As far as non-medical services are concerned, examples of innovations falling within the scope of these trajectories would include the development of cleaning protocols adapted to the needs of hospitals (and in particular protocols for dealing with toxic waste), the introduction of a quality procedure among teams of stretcher bearers, the development of measures to combat the forging of medical prescriptions and the design of trend charts for quality and risk management. Turning now to medical services, these trajectories denote the development and improvement of diagnostic protocols, treatment protocols, therapeutic strategies and hygiene protocols (including those drawn up to combat nosocomial diseases).

The relational trajectories are difficult to separate from the others. All attempts to increase customer/patient loyalty (particularly in private hospitals) fall within the scope of both methodological and relational trajectories. Innovations in internal and external systems for transporting equipment and people (self-propelling vehicles, wheelchairs, robots, etc.) probably fall within the scope of both material and relational trajectories. The experiments with interactive communication and payment stations that many hospitals have conducted seem to us to fall within the scope of this relational trajectory; at the same time, in view of the technologies they mobilise, they also contribute to the informational trajectory.

d) The combinatory principle

The combinatory principle is the one most frequently encountered. It can manifest itself at various analytical levels. 
It is at work in the frequent hybridisation in hospitals between the material trajectories and informational trajectories. Microelectronics and computer technology have gradually permeated all material operations, from medical instrumentation to transport systems for equipment or patients. Examples of hybrid medical technologies include computer-aided diagnostics, medical monitoring, automatic diagnostic equipment and video surgery. Imaging (MRI, scanography, video endoscopy and nuclear medicine, particularly scintigraphy) is often regarded as the medical technology that has benefited most from progress in IT (signal processing), automatics and video. The pervasive and generic aspect of the informational trajectory (that is, its capacity for hybridisation not only with the material trajectories but also with all the other trajectories) is illustrated by the recent establishment of highly automated, so-called digital hospitals.

The combinatory principle can also be seen at work in the development of a new type or concept of hospital. The creation of a new hospital (for example, the Jeanne de Flandre hospital in Lille) follows this combinatory principle and extends over a considerable area of the table.

Most experiments with network-type structures (community health networks, coordinated care networks, etc.) also fall within the scope of the combinatory principle. Such experiments involve the combination of a greater or smaller number of constituent services and increases in the scope of innovation trajectories and the creation of multiple linkages between them. They vary considerably in terms of the number of actors involved, the nature of those actors, their objectives and the technologies mobilised.

These networks vary in their level of sophistication. They range from the simple joint acquisition of expensive equipment by several hospitals or agreements on the shared use of equipment such as scanners or MRI machines to more complex undertakings, such as hospital mergers, the takeover of one hospital by another or the establishment, within hospitals or close to them, of units intended to create links with generalists. These might include geriatric units run by general practitioners and social workers from outside the hospital and walk-in treatment centres for minor emergencies operated and managed by doctors and nurses from outside the hospital.

\subsection{Retailing industry}

The core service provided by the retail industry is the distribution of goods. However, the truly characteristic feature of the retail sector is that it offers a package of other constituent services (catering, logistics, leisure activities, banking services, insurance services, etc.). Clearly, we are dealing here with an 'assembled' service, in which the various organising principles driving innovation highlighted by our analytical model are at work. ${ }^{3}$

a) The extensive principle

\footnotetext{
${ }^{3}$ A detailed analysis of the innovation dynamic in the retailing and distribution industry, with abundant illustrations, is offered by C. Gallouj (2005).
} 
There is an abundance of examples to illustrate the extensive principle, which involves the addition of constituent services (Si) to a given package, or the addition of services (sij) within this constituent service. At the intra-organisational level, that is that of the constituent service (and confining ourselves to the core constituent service, namely the distribution of goods), the following examples can be cited: packing bags at the checkouts, home deliveries and the proliferation of specialist departments and individualised services. At the organisational or inter-organisational level, the introduction of crèches, the introduction of financial and insurance services and the opening of travel agencies and petrol stations can all be cited as examples.

\section{b) The regressive principle}

The regressive principle, conversely, involves the elimination of constituent services. This is the principle driving the establishment of discount stores, as opposed to traditional supermarkets. Just like the highly specialised clinics mentioned above, the opening in 1999 (by the Auchan group) of the first hypermarket dedicated exclusively to the sale of drinks ('La Cave d'Auchan') or the launch the following year of the 'hyper drive-in' ('Auchan Express') can also be regarded as falling within the scope of this principle (Gallouj, 2004). The regressive and extensive principles lie at the heart of certain well-known theories of innovation in retailing, particularly the wheel of retailing theory (McNair, 1958) and accordion theory (Hollander, 1966), which describe the historical dynamic of retail formats in terms of a dialectic between trading up (extension of product range and the provision of new services) and trading down (severe restriction of product ranges and reduction in the services provided).

\section{c) The intensive principle}

The intensive principle can be considered in historical terms. Thus from the 1940s and $50 \mathrm{~s}$ in the USA and the 1970s in France, supermarkets followed a natural technological trajectory characterised by increasing mechanisation and the exploitation of economies of scale based on two basic innovations: self-service and the establishment of chains. For a long time, the innovation model in use focused on the material transformation function of the product $(\mathrm{M})$ (introduction of Fordist logistical systems) and on strengthening the self-service relation (R); in a second phase, the focus switched to the information processing function (I).

Going beyond the historical dimension, the existence of four innovation trajectories falling within the scope of this intensive principle can be illustrated in a more systematic way.

Thus the professional literature regularly reports on innovations falling within the scope of the material trajectory that have been introduced in the retail industry. The most spectacular innovations in this sphere usually pass unnoticed by consumers. They involve technologies deployed to assist in the industry's logistics operations, for example the automation and robotisation of stocks and stockrooms (use of pallets and material handling robots, installation of storage platforms etc.). They also involve technologies used for food conservation and management of the cold chain, cooking technologies, cutting technologies and surface cleaning technologies. Mention could also be made of some more or less sophisticated technologies deployed in the "front 
office' (i.e. in customer facing applications), for example the introduction of new types of trolleys.

The informational trajectory is playing an increasingly important role in the retail industry. The corresponding innovations, which emerged initially in the fertile ground of administrative and management services, have spread gradually to all areas of the industry, both upstream (relations with suppliers) and downstream (relations with customers). Thus there are numerous examples of new information technologies applied to the retail industry (C. Gallouj, 2005) : information generators (point of sale terminals), decision-making aids (advice terminals, labels etc,) point of sale management tools (back office), computerised sales kiosks, payment systems activated by digital fingerprints, self-scanning, virtual tailors' dummies used for virtual clothes fitting, computerised present pickers or gift assistants (interactive terminals which, when certain information is entered, help consumers select a present and locate it within the store). EDI and ECR are probably the best-known examples of technologies falling within the scope of this informational trajectory.

The retail and distribution industry also provides examples of innovations falling within the scope of the methodological trajectory. It is fertile ground for the development of new sales techniques and methods, the introduction of specific creative processes, etc. Some retail groups have also set up subsidiaries specialising in providing retail consultancy services. These subsidiaries are perfectly capable of adopting the same methodological trajectories as all consultants.

For a long time, the retail industry's development trajectory was predicated on reducing customer contact (intensification of self-service). Now, in contrast, the trend is towards a proliferation of direct customer services, customer contact and opportunities for customer contact. Thus innovation in retailing is also drawing on developments that fall within the scope of the relational trajectory $(\mathrm{R})$. This applies, for example to all strategies for improving 'social relations' through the introduction of loyalty, credit or advantage cards, the use of 'greeters' (employees whose job is simply to greet customers at store entrances ${ }^{4}$ ), etc. Another example falling within the scope of this trajectory is the recent launch in France of the 'hyper drive-in'.

d) The combinatory principle

The combinatory principle is by far the dominant one. Even though they constitute valuable levels of analysis, the various trajectories considered above are often called into question by careful analysis of specific cases of innovation. Hybridisation can be seen at work everywhere in a number of different forms.

Thus the material and informational trajectories are becoming increasingly intertwined and giving rise to hybrid configurations. EDI and, more recently, ECR (Efficient Consumer Response) are playing an important role in this hybridisation. One simple example of hybridisation between the material and informational trajectories is provided by the so-called 'smart trolley'. This is a trolley fitted with a touch screen that can display a plan of the store, the position of the trolley and a certain amount of general information, such as current promotions, for example.

\footnotetext{
${ }^{4}$ This practice, which is developing in the USA, is fairly widespread in Japan.
} 
However, this hybridisation is even more marked between the relational trajectory and the two other trajectories, since many new services involving customer contact are incorporated in or closely linked to material or informational systems and cannot be considered outside of those systems. This applies to interactive information and orientation terminals, new telesales or teleshopping services, automatic vending machines, self-scanning etc.

The combinatory principle is also at work in the launch of new hypermarket concepts. A recent example is the opening of the Auchan of Marne la Vallée (nicknamed H3M: the hypermarket for the third millennium), which combines organisational innovations (world of consumption) with architectural, ergonomical, technological and service innovations in order to test the commercial relationship's new informational paradigm, which seeks to reconcile low prices with a high service levels (for a detailed analysis, cf. C. Gallouj, 2005). Similarly, this combinatory principle manifests itself (at the inter-organisational level) in all the (new) strategies for opening up hypermarkets to their environment: producers, suppliers, various service providers etc. Thus co-branding (jointly managed brands), joint supply chain management (involving producers and distributors), cross-docking (in which responsibility for preparing orders for each point of sale is transferred to the supplier) or even some of the partnerships established between the distributors and operators of telephone services or financial services fall within the scope of this principle.

\subsection{Theme parks}

This third illustration of our model is based essentially on an empirical investigation carried out at Euro Disney SCA, a multinational group in the leisure and tourism industry, based in America, which owns and operates many themes parks across the world and is a major player in the cinema and television industry. A theme park's operations combine various traditional services: attractions, live entertainment, cinemas and discotheques, as well as hotels, restaurants, transport and traffic flow management (internal and external), shops, conference centres, cleaning, security, etc. The Parisian theme park, which is the leading European tourist destination, comprises more than 40 attractions divided into five destinations or 'lands': Adventureland, Discoveryland, Fantasyland, Frontierland and Main Street USA, and seven hotels, each themed around a famous place. Within the Disney group, there is a group whose job it is to design new attractions for the theme parks. For example, when a new film is about to appear, this group investigates how the film's theme might be incorporated into a new attraction.

Within the Disney company, there is a wide diversity of types of innovation and forms of R\&D or similar activities, which can be adequately accounted for by our analytical framework, both descriptively and in terms of likely future developments.

The extensive and regressive principles act on the rows of the table. They involve the addition (or subtraction) of constituent services at the organisational, intraorganisational or inter-organisational levels. Examples would include the addition of new live entertainments, new attractions etc., with the new services very often replacing existing ones. Thus the extensive and intensive principles go hand in hand. 
The intensive principle finds expression in the introduction of various types of technologies into the constituent service activities under consideration. It acts on the columns of the table.

This intensive principle may follow a material trajectory. There follow some examples that fall within the scope of this trajectory:

- the development of means of internal transport adapted to the specific needs of theme parks;

- the development of non-polluting fireworks - whether the pollution be chemical or noise-related. The aim was to find substitutes for explosives (pneumatic launching) and non-polluting colouring systems.

- research on extending the operational life of theme park equipment. Topics that have been investigated include the longevity of the paints used on various items of equipment (e.g. railings), their resistance to different climatic conditions (sun, damp), etc.

- research by chemists with the aim of developing more effective and environmentally-friendly cleaning materials.

- attempts to improve, particularly from the chemical point of view, the animatronic figures developed by Walt Disney from the 1950s onwards ${ }^{5}$.

The intensive principle may also follow an informational trajectory: hotel or transport reservation systems; computer systems for managing queues at the attractions, portable electronic customer guidance and information systems, etc. The following, more specific examples can be cited:

- Innovation in projection equipment (art tech equipment) and in new generations of loudspeakers.

- The development and launch of Disney Quest, a mass-market interactive video game which required significant investment in R\&D in NICTs.

- Fast Pass, which is regarded as the most significant innovation in the industry for several years. It is a computerised queue management system that functions as a reservation system ${ }^{6}$.

Innovation may also follow a methodological trajectory. In this case, it involves the introduction of intangible or 'invisible' technologies. They take the form of organisational processes, methods and scripts. The latter term applies not only to the various live entertainments that are a feature of theme parks, but also to all the other constituent service activities, such as hotel and catering services, to the extent that they are conceived as genuine 'performances'. Examples of these methodological innovations include the decentralised management model known as 'Small Worlds'. Euro Disney is indeed managed on the basis of the 'Small Worlds' principle, that is autonomous profit centres (e.g. a bar, a restaurant, a reception desk, a housekeeper, a head cook, etc.). All Small World managers have to manage their parts of the business

\footnotetext{
${ }^{5}$ They are robots that look like real human beings, are powered by hydraulics and have a flexible skin, which can be painted and modified. Research has been carried out with the aim of increasing the operational life of this artificial skin, which tends to deteriorate rapidly.

${ }^{6}$ Customers put the ticket they receive at the entrance to the theme park into the corresponding terminal at a given attraction. This terminal issues them with a new ticket offering them a time slot within which they will be able to get into the attraction in question through the special Fast Pass entrance, thereby avoiding the queue.
} 
in accordance with three sets of targets that are applied at all levels of the business up to the vice-president. These are financial targets, quality targets and management targets.

It should be noted that the Show Quality Standards (SQS) group already alluded to above is responsible for maintenance of the intangible technologies, which means adherence to the 'scripts', that is the role each person plays in the whole 'performance': customers ('guests'), as well as employees ('cast members'). The SQS group guarantees compliance with the basic principles of the product. It is responsible for preventing attractions from 'deviating' from the script over time or as a result of changes in cast members.

The relational trajectory, for its part, is combined with others, as is frequently the case. Thus the purpose of research into environmental problems and of any ensuing innovations is clearly a relational one, namely to increase customer loyalty and establish relationships of trust. Technological innovations resulting in improved queue management are also consistent with this relational principle.

Usually, of course, innovation in this type of activity is driven by a combinatory principle involving different types of technologies and different types of constituent services. Thus the introduction of a new attraction involves both the introduction of new technical systems and the production of new scripts for the providers of the attraction (or actors) and for those selling the products and services derived from it.

The establishment of a new park also falls within the scope of the combinatory principle. Its creation may take a number of different forms. Attractions existing elsewhere may simply be reproduced and combined. This was the case with the Hong Kong Disneyland, most of whose attractions come from other parks, with the novel element lying in the social and cultural packaging and presentation. A number of cultural problems (traffic flows, eating habits, specific needs) had to be resolved, which required certain sociological and psychological investigations to be carried out. On the other hand, Tokyo Disney Sea, one of the two theme parks in the Tokyo Disney Resort, which is dedicated to the theme of water and the ocean, is a totally original project. Most of the attractions were developed in the company's research laboratories. The project required many years' collaboration with the Japanese.

At another level of analysis (the intra-organisational level), the constituent attractions themselves usually take on a combinatory aspect, as the following examples demonstrate. 'Space Mountain' is an attraction developed in the Florida Disneyland. It was launched in Paris in 1995. The Paris Space Mountain is very different from the one in Florida. The difference lies not in the technical systems used (catapults) but rather in the packaging and presentation. In Florida, the ride can be reduced to a simple catapult, whereas in France it 'tells a story', namely that told in Jules Verne's novel 'From the Earth to the Moon'. The visuals, the machinery (catapults in this case) and the music all help to give visitors the impression that they are going on a journey to the moon. Thus the ride (and its design) cannot be reduced to a series of catapults, that is to technical systems. What is of greater importance, for the narrative, is the way in which the organisation of the ride, the scripts and the each participant's role have been conceived. Thus all the 'cast members' who work on Space Mountain wear clothes inspired by Jules Verne's novel, use a particular vocabulary and have a 
specific way of talking to each visitor. The organisation is particularly complex. It is the result of intense intellectual activity located midway between artistic creation (stage play) and research or design-development (Djellal et al. 2003). The technical, organisational and behavioural aspects are all closely intertwined. These principles apply not only to the attractions but also to the hotel and catering services.

\section{Conclusion}

The framework developed in this paper is general in its scope. Although we have illustrated it largely by means of examples taken from the hospital sectors, the retailing and distribution industry and theme parks, it could equally well be applied to all 'assembled' or 'packaged' services, and even to certain sectors such as construction and public works (Carassus, 2005; Bröchner, 2006). This framework can be used to interpret innovation at three different levels, namely the organisational, intra-organisational and inter-organisational levels. It can be used both as a tool to audit what already exists and as an instrument for identifying potential for future innovations.

Thus it can be used to identify the multiplicity of forms of innovation in 'assembled' services, and in particular to eliminate the common analytical bias (which reflects the power relations within organisations) whereby the potential for innovation is confined to basic services and the actors involved in providing them. The framework reveals that innovation is not the exclusive preserve of a particular function (and of the professionals attached to it) and that it does not manifest itself solely in tangible and spectacular technological forms. Innovation not only covers the whole of the area marked out by our analytical grid but can also change the size of that area, depending on the type of organising principle brought into play. The extensive and regressive principles involve, respectively, adding or eliminating a new constituent service. The intensive principle involves extending or improving a given technological component of the product, while the combinatory principle, which is more frequently encountered, links the other principles and produces innovation by combining (associating and/or separating) different constituent services and/or different technologies.

Nevertheless, our analytical grid should not give rise to a fragmented and mechanical view of organisations and innovation. In our view, the suggested decompositions are useful heuristic devices, but they may well impoverish the analysis if they are used in a mechanical way that empties organisations of their social substance. In other words, links and relationships exist everywhere and they cannot be severed.

\section{References}

Berry, M. (1983) Une technologie invisible : l'impact des instruments de gestion sur l'évolution des systèmes humains, Paris : CRG.

Bougrain, J., Carassus, J. (2005), Innovation in the construction, management and operation of non residential buildings: elements to analyse and evaluate innovations, Swedish and French Seminar "Service Innovation Theories and Construction », Paris, 21 November.

Bressand, A., Nicolaïdis, K. (1988), 'Les services au cœur de l'économie relationnelle', Revue d'économie industrielle, 48, pp. 141-163. 
Bröchner, J. (2005), Innovation among construction contractors : theoretical foundations of empirical surveys, Swedish and French Seminar «Service Innovation Theories and Construction », Paris, 21 November.

Bröchner, J. (2006), 'Between services and goods: innovation among construction contractors', CRIC Conference on "Innovation in services ", Manchester, june.

Djellal, F. (2000) 'The Rise of Information Technologies in "Non-informational» Services', Vierteljahrshefte zur Wirtschaftsforschung, 4-69. pp. 646-656.

Djellal, F., Francoz, D., Gallouj, F. and C., Jacquin, Y. (2003) 'Revising the definition of research and development in the light of the specificities of services', Science and Public Policy, vol 30, n 6 , december, pp. 415-430.

Djellal, F., Gallouj, C., Gallouj, F., Gallouj, K. (2004) L'hôpital innovateur : de l'innovation médicale à l'innovation de service, Editions Masson, Paris.

Djellal, F., Gallouj, F. (2005) 'Mapping Innovation Dynamics in Hospitals', Research Policy, 34, pp. 817-835.

Gadrey, J. (1996) L'économie des services, La découverte, Paris.

Gadrey, J. (2000) 'The Characterization of Goods and Services : an Alternative Approach', the Review of Income and Wealth, 46, $\mathrm{n}^{\circ}$ 3, september, pp. 369-387.

Gallouj, C. (2005) Socio-économie de l'innovation: une application au grand commerce, Clersé, University of Lille, 354 p.

Gallouj, F. (1994) Economie de l'innovation dans les services, L'Harmattan, Paris.

Gallouj, F. (2002) Innovation in the Service Economy: the New Wealth of Nations, Edward Elgar Publishers, Cheltenham, UK, Northampton MA, USA.

Gallouj, F. and Weinstein, O. (1997) 'Innovation in services', Research Policy, 26, pp. 537-556.

Gallouj, F. (1999) 'Les trajectoires d'innovation dans les services: vers un enrichissement des taxonomies évolutionnistes', Economies et Sociétés, série EGS, $\mathrm{n}^{\circ} 1, \mathrm{pp} .143-169$.

Hill, P. (1977) 'On Goods and Services', the Review of Income and Wealth, 4-23, pp. 315-338.

Hill, P. (1999) 'Tangibles, Intangibles and Services : a New Taxonomy for the Classification of Output', Canadian Journal of Economics, 32, $\mathrm{n}^{\circ} 2$, April, pp. 426-444.

Hollander, S. C. (1966) 'Notes on the Retail Accordion', Journal of Retailing, Vol. $42, n^{\circ} 2$, pp. 24-34.

Lenfle, S., Midler, C. (2003) 'Innovation in automative telematic services: characteristics of the field and management principles', International Journal of Automative Technology and Management, Vol. 3, n 1/2. pp. 144-159

McNair, M.P. (1958) Significant Trends and Developments in the Postwar Period, in Smith A.B. (ed.), Competitive distribution in a free high level economy and its implication for the university, University of Pittsburgh Press, Pittsburgh, pp. 1-25.

Metcalfe, J.S., Miles I. (eds) (2000), Innovation systems in the service economy, Kluwer Academic Publishers.

Nahon, D., Nefussi, J. (2002) Les services au cour de l'innovation dans la production agricole: l'exemple de la pomme de terre, in Djellal, F. Gallouj, F. (eds.), Nouvelle économie des services et innovation, L'Harmattan, Paris, pp. 285-300.

Nelson, R., Winter, S. (1982) An Evolutionnary Theory of Economic Change, Belknap Harvard, Cambridge, Mass. and London.

Sasaki, L. (2003) 'Hospital Offer unconventional services in hopes of attracting future patients', Hospital Quarterly, Spring, 6(3), pp. 85-86. 
Sundbo, J. (1998), The Organisation of Innovation in Services, Roskilde: Roskilde University Press.

Sundbo, J., (1996), 'Development of the service system in a manual service firm: a case study of the Danish ISS', Advances in Services Marketing and Management, 5, pp. 169-191.

Swindley, D., Thompson, C. (1992) 'Hospital Retailing', The Service Industries Journal, 12(2), April, pp. 210-219.

Teboul, J. (1999) Le temps des services, Les Editions d'Organisation, Paris.

Toivonen, M. (2004) Expertise as business: Long-term development and future prospects of knowledge-intensive business services, Doctoral dissertation, Helsinki University of Technology. 